\title{
Contextual attributes to promote positive social interdependence in problem-based learning: a focus group study
}

\author{
Ikuo Shimizu ${ }^{1 *}$, Yasushi Matsuyama ${ }^{2}$, Robbert Duvivier ${ }^{3}$ and Cees van der Vleuten ${ }^{4}$
}

\begin{abstract}
Background: Problem-based learning (PBL) is classified as a collaborative learning approach, wherein students learn while contributing meaning to experiences and interactions with others. An important theoretical fundament of PBL is social interdependence theory (SIT) because positive social interdependence within a group has been found to be key to better learning performance and future attitudes towards team practice. However, most previous studies in health professions education focused on cognitive outcomes, and few studies have focused on collaborative behaviors in PBL groups. The lack of this empirical insight makes implementation of PBL difficult, especially in contexts where there is limited experience with collaborative learning. Therefore, the aim of this study was to elucidate what promotes or hinders positive social interdependence and how the attributes work during PBL.

Methods: We conducted four focus groups among clinical year medical students $(n=26)$ who participated in PBL tutorials in the formal curriculum. We asked semi-structured questions that corresponded with the overall concept of SIT. We analyzed the transcript using constructivist grounded theory and developed a model to explain contextual attributes that promote or hinder positive social interdependence in PBL.
\end{abstract}

Results: Two contextual attributes of "academic inquisition" and "desire for efficiency" affect social interdependence among a student group in PBL. Academic inquisition is students' desire to engage in their academic learning, and desire for efficiency is students' attitude toward learning as an imposed duty and desire to complete it as quickly as possible. These attributes are initially mutually conflicting and constructing social interdependence through multiple steps including inquisition from a case, seeking efficient work, sharing interest in problem solving, expecting mutual contributions, and complementing learning objectives.

Conclusion: These findings will contribute to understanding collaborative learning environments in PBL and may help explain contexts where PBL is less successful. The model can also be used as a tool to support innovation of PBL as collaborative learning.

Keywords: Collaborative learning, Health professions education, Problem-based learning, Social interdependence theory, Qualitative research

\footnotetext{
* Correspondence: ishimizu@shinshu-u.ac.jp

'Center for Medical Education and Clinical Training, Shinshu University, 3-1-1

Asahi, Matsumoto 3908621, Japan

Full list of author information is available at the end of the article
}

(c) The Author(s). 2021 Open Access This article is licensed under a Creative Commons Attribution 4.0 International License, which permits use, sharing, adaptation, distribution and reproduction in any medium or format, as long as you give appropriate credit to the original author(s) and the source, provide a link to the Creative Commons licence, and indicate if changes were made. The images or other third party material in this article are included in the article's Creative Commons licence, unless indicated otherwise in a credit line to the material. If material is not included in the article's Creative Commons licence and your intended use is not permitted by statutory regulation or exceeds the permitted use, you will need to obtain permission directly from the copyright holder. To view a copy of this licence, visit http://creativecommons.org/licenses/by/4.0/ The Creative Commons Public Domain Dedication waiver (http://creativecommons.org/publicdomain/zero/1.0/) applies to the data made available in this article, unless otherwise stated in a credit line to the data. 


\section{Introduction}

Problem-based learning (PBL) has been utilized in global professional health education for more than 50 years. It is classified as a collaborative learning approach, wherein students learn while contributing meaning to experiences and interactions with others $[1,2]$. The quality of discussions within tutorial groups make significant contributions to the success of PBL [3]. In group discussions, for learning outcomes to be achieved, there must be group dynamics that involve participant cooperation.

Since group dynamics are essential for small group discussion, social interdependence theory (SIT) has been applied to PBL as one of theoretical frameworks" [4]. In this theory, social interdependence exists when the outcomes of individuals are affected by their own and others' actions, and the process to structure positive and negative interdependence is divided into three categories: outcome, means, and boundary [5]. Outcome interdependence is defined as orientation toward goals and rewards. Means interdependence includes resources, roles, and task interdependence. Resources are used among group members, some of which are utilized as joint property. Roles are assigned to group participants, such as readers, recorders, summarizers, and encouragers. Task interdependence can be created when the group members come to mutual agreement regarding how to divide and assign the tasks, making each group member responsible for their learning objectives. This leads the learning group to be more productive. Boundary interdependence is based on abrupt discontinuities among individuals, and thus includes identity and environment (such as a working area) [4].

There are positive (the actions to promote the achievement of joint goals) and negative (the actions to obstruct the achievement of each other's goals) types of social interdependence. Positive interdependence is a key for successful collaborative learning [6] because positive interdependent cooperation does results in more frequent use of higher-level reasoning, more interpersonal relationships, and greater social support [5]. Furthermore, social interdependence is important in health professionals so that they construct relationships between intra- and interprofessional care providers, trainees and trainers and patients [7]. This is a reason why some medical educators $[8,9]$ wanted to cultivate positive social interdependent attitudes among learners through PBL.

However, we have little knowledge regarding what promotes or hinders positive social interdependence in PBL. Most previous PBL studies paid attention to aspects of cognitive outcomes, and only few studies have focused on collaborative behaviors in PBL groups [10]. Although the results of PBL can be observed through behavioral and psychological changes [11-14], it is unclear which details in PBL augment social interdependence. The lack of this explanation makes it difficult to correctly implement PBL and the challenge can be seen in different parts of the globe, as for example, Asia [8]. In a Japanese medical school, Oda and Koizumi [15] faced difficulties such as superficial discussion and significant differences in learning attitudes among students, as well as limitations in tutors' skills. Khoo [16] described how Asian contextual characteristics might be incompatible with discussions in PBL. It might be because the existing educational systems and environments were incompatible with PBL [17]. However, they have not been able to explain why the educational system and environment were not compatible with the collaborative characteristics in PBL because the promoting and inhibiting factors of social interdependence in the PBL groups have not been sufficiently clarified from the perspective of SIT. If we can explain collaborative behavior in PBL using SIT, we will be able to analyze the functioning of $\mathrm{PBL}$ in various contexts and therefore propose methods to optimize PBL in individual contexts. The aim of this study, therefore, was to elucidate what promotes or hinders positive social interdependence and how social interdependence functions within the PBL group.

\section{Methods}

This study employed a constructivist grounded theory approach [17] to elucidate social interdependence that students had cultivated during PBL, based on an interpretivist paradigm that reality is context-dependent and that multiple interpretations can be constructed among people [18].

Participants included fourth-year medical students of the six-year undergraduate medical curriculum in Shinshu University, Japan. The hybrid curriculum included lectures and collaborative learning opportunities followed by the PBL. The students had completed a set of PBL tutorials (comprised of two tutorial sessions) during the internal medicine II clinical rotation and participated in targeted PBL as a part of the formal curriculum. The PBL covered clinical reasoning of hematology cases and was conducted in concordance with the original seven-step approach [1], as accurately as possible. One author (IS) served as a tutor to avoid wide variance in tutoring skills during the discussions. Since there could be criticism that Asian faculty have conducted PBL differently under the teacher-centered and examination-based learning culture $[8,19]$, the tutor has understood the notion and tried not to let the power difference affect the discussions and reflect his facilitation. The PBL tutorial is not related to the grading of students; summative assessment during the internal medicine rotation was workplace-based with clinician- 
educators, then the students will take summative graduation test after completing all of the clinical clerkship rotations. The PBL tutorial in this study was only used for formative assessment.

Data collection and analysis then occurred in an iterative fashion. We asked students to participate in the research before initiating PBL and conducted focus groups comprised of students who were accepted as study participants. We used theoretical sampling [20] based on an assumption that some students had favorable perception on collaborative learning while others may not. We formed a focus group with the same members as the respective PBL groups because we wanted to stimulate them to recall the interactions between the participants during their discussions [21].

A semi-structured focus group was conducted after the entire PBL sessions were completed. Informed consent was obtained as declared in the ethical consideration. During the focus groups, the primary researcher (IS) asked participants questions (see Additional file 1) and recorded all conversations during the sessions. $\mathrm{He}$ was exempted from summative assessment of the clerkship to allay the concern that participants' comments during responses might affect their assessment. An administrative clerk helped organizing and assisted recording the focus groups, and another researcher (YM) checked the recorded data before coding for triangulation.

Questions used in focus groups were formulated to correspond to the overall concept of social interdependence in collaborative learning and the three components of SIT [4]. The first question cued participants to recall words and actions that helped the group, or conversely, that helped them study independently. The focus group continued with a discussion that followed the questions shown in the interview guide (see Additional file 1).

The interview guide was periodically revised in light of the developing analytical process by researchers (IS and $\mathrm{YM}$ ). Iterative comparison was conducted by comparing the data with the previous group until saturation was reached $[17,22]$. We initially enrolled students who were interested in giving an active opinion about the group discussion, and conducted three focus groups during the 2017-2018 clinical clerkship program. Then we conducted one more focus group to obtain more rigor from members of a PBL group who perceived their collaboration did not work well during their discussion in 2019, in case the students who voluntarily participated in the discussion might make good use of the group discussion. Every focus group took 45-60 min. Ultimately, $26 \mathrm{stu}-$ dents were enrolled until saturation, comprising four focus groups in total. The participants consisted of 17 males and 9 females, which showed a comparable male/ female ratio to this medical school (2.07 in 2020).
Median age was 23 (range: 21-36). All recorded interviews were subsequently transcribed by a research assistant service.

Coding and categorization with theoretical sampling and repetitive comparison were conducted as the processes of constructivist grounded theory to elucidate the contextual attributes that may promote or hamper social interdependence in the PBL. We referred to items in the social interdependence in collaborative learning scale [23] for the coding process because it includes several behaviors congruent with the three components of SIT. We chose open and axial coding based on the definition of social interdependence [4] without using the framework or three components of SIT because there has been no prior literature to explain the specific processes in line with them. Coding as well as inductive categorization, were conducted by the two authors (IS and YM) in Japanese. They initially read the transcript and coded individually for triangulation, and then reviewed and matched them together. This process was conducted iteratively. Since the first author was also a tutor, he took a memo for his reflection on the process and the researcher's role and influence after each interview and when reading the transcript to ensure reflexivity. Representative speech-supporting codes were translated once into English in the selective coding phase and a proof reading service then confirmed translation. The other authors (RD and $\mathrm{CvdV}$ ) contributed to develop the manuscript through discussion. We used Microsoft Excel throughout the coding process.

\section{Results}

Through the analysis of the audio transcripts, we identified two different types of contextual attributes that affect the fundamental concept of social interdependence. The first attribute refers to students' interest in engaging and deepening their academic learning. The other attribute refers to students' attitude that they regard learning contents as imposed duties, and want to complete them as minimal time and effort as possible. These are initially perceived as mutually conflicting concepts in constructing interactions. Thus we named "academic inquisition" and "desire for efficiency" as two contextual attributes that promote or hinder positive interdependence of students in PBL, and regarded as the key themes in the result of the research.

Figure 1 depicts the five steps that these contextual attributes above (academic inquisition and desire for work efficiency) affect social interdependence during the PBL sesions. In this model, students' inquisition from a case was provoked, and they felt compelled to proceed with their learning. Simultaneously, they regarded PBL as one of the duties and wanted to seek an efficient work process to complete the work as quickly as possible. As 


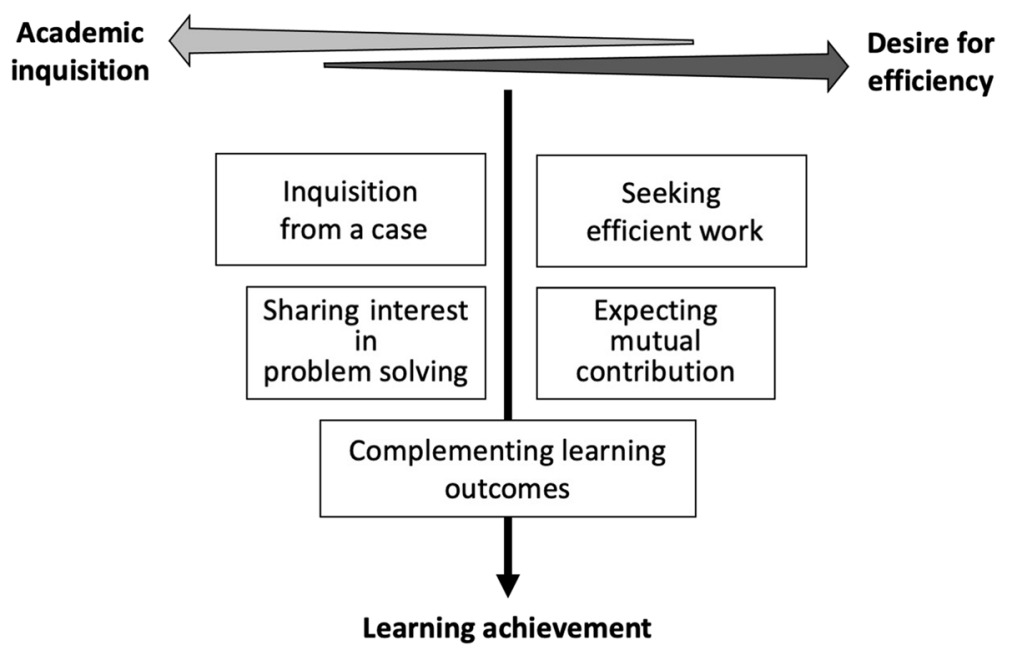

Fig. 1 The two contextual attributes that promote or hinder positive interdependence of students in PBL, and the five steps that the contextual attributes affect social interdependence during the discussion

a result, they were willing to share their academic problems and work together to solve the problems even though they were not familiar with each other. They also expected each other's contributions to increase efficiency. Eventually, they considered their sharing and contributions resulted in the socially interdependent behavior of complementing the learning outcomes.

We categorized the inquisition from a case and seeking efficient work steps as attitudes that prioritize academic inquisition and desire for efficiency, respectively. The subsequent sharing interest in problem solving and expecting mutual contributions were rooted in these attributes, respectively, but were created through expectations of others' behavior as PBL processes progressed. The final behavior resulted in complementing learning outcomes. Although we also observed other minor items which emerged less frequently, they were considered either subsets of the steps or unrelated to our aim (e.g. comments on clinical clerkship).

The following sections explain the five steps to establish positive social interdependence during PBL. Representative quotes are presented below to exemplify each step.

\section{Inquisition from the case}

The students were initially motivated by what they found interesting in their cases that drove their learning process. They were aware of the significance of sharing their problems with other students, who might have different interests from their own. These behaviors were categorized as inquisition from the case.

My initial purpose of PBL was supposed to be to study myself, but when I started PBL and started to work on case studies, I felt emotions like "this is really interesting" and "I want to share my emotions". As soon as you are interested in the case, you want to tell others about it.

As I do, each person has their own problems that they find from this case, so by being aware that others have other perspectives on things that you haven't gone to see, you will be able to pay attention to them.

\section{Sharing interest in problem solving}

The students believed that they needed to share their own insights, which was derived from their inquisition. They also wanted to share questions related to achieving academic goals as they believed that this would help create PBL. These behaviors were categorized as sharing interest in problem solving.

I want to share my opinions because I expect groups to make me aware of points I don't notice, and that's what I'm looking for in a group. In addition, I think it's easier to move on to the next step if we see the same things and build consensus on moving forward as group work, rather than having it all to ourselves.

I didn't care that the patient in my case today has hypernatremia. So if you don't speak up with the assumption that everyone will understand the problem, it's a risk to the group. That (speaking up) is what I think learning in PBL is all about. 


\section{Seeking efficient work}

While the students were interested in the cases, PBL was perceived as a mandatory task to be completed as a part of the regular curriculum. Therefore, students wanted to complete it as efficiently as possible. They believed that a knowledgeable facilitator would be able to help drive efficient progress. These behaviors were categorized as seeking efficient work.

Since it's group work within a set amount of time, I think it would be more efficient if the person with more knowledge would take the lead and have a better time to complete the tasks, which would increase the overall efficiency.

I thought that someone who can do better than me should do to moderate. If there is someone like that in there, I shouldn't be the one to do it. It's faster or more efficient. (What do you mean "do better" ?) Having some knowledge on the theme. We could do it more quickly if there were such a person.

\section{Expecting mutual contributions}

Each student tried to find interesting points in the cases and also to estimate their level of understanding regarding the topic for efficient work process. It did not matter that the students had different levels of understanding; instead, they found it important to identify those differences and contribute appropriately to the learning process so that the learning could be completed. This was referred to as expecting mutual contributions.

I show everyone what I know. Often, others will point out things that I didn't notice or something else, so I may show them hoping that they will notice something I didn't notice.

One of the advantages of group learning is that you can get ideas from other people you didn't have when studying alone. For example, even if you are working as a doctor in clinical practice, the nurses will speak from a different perspective, so it's worth listening to them and expecting their opinions.

\section{Complementing the learning outcomes}

Finally, the students attempted to achieve more meaningful learning outcomes by complementing their academic achievements with the achievements of others. They believed this would increase their learning and improve their learning efficiency through mutual contributions. These behaviors were categorized as complementing the learning outcomes.

(How did you decide on your academic objectives?) As all of us weren't sure about the lung images, we all agreed to do it together. But other than that, we went over each of the things we had listed and the things we wanted to look into, and then we decided on the learning objectives for each of us.

I'm responsible for my own learning goals because I chose them, and since there are five of us, I'm sure the other four will learn properly, and that's the brake on me. I don't want to be lazy or wonder if that's enough, but I want to prepare myself so that I don't have to be disrespectful to someone else who has been working harder than me have to be prepared for that. Motivation from the inside is important, but there is also motivation from the outside, which is created by others' presence, and I feel that this is an advantage of learning in a group.

Conversely, there were some students who felt that they could not expect contributions from others or could not achieve more than their own learning through the group discussion. They did not establish social interdependence and were instead oriented toward individual learning. While they were interested in learning, they did not find group learning to be efficient. Others were so concerned with learning efficiency that they were distracted by the opinions of their tutors, who should have known the conclusions, rather than their own interests.

What makes a person grow the most is when he or she is in a group. But there are times when I think I'm better off on my own than in that group. Although individual learning is the next best thing, there have been few moments when I've learned in a group where I've been able to surpass my own efforts, so it's tempting to prioritize my own learning.

I was inclined to discuss it, but I was too conscious of reacting to the tutor's advice. I was thinking about reaching the end the tutor had for us rather than setting our own academic goals.

\section{Discussion}

This study revealed contextual attributes that promote positive social interdependence during PBL and how they function. Two attributes that affect social interdependence were uncovered: academic inquisition and desire for efficiency. Then we explained the processes to 
work the attributes with five steps. Ultimately, these attributes culminated in the interdependent behavior of complementing each other's learning outcomes.

PBL is said to foster positive social interdependence $[24,25]$. This study revealed the process by which this occurs by analyzing a PBL program in a Japanese context. We begin by discussing whether the results are consistent with SIT as a theoretical framework and its components (outcome, means, boundary) [5]. First, the students' academic interest in the case attracted their attention and made them seek out problems to solve. Simultaneously, the students consider solving the problems to be a task that was completed in a fixed curriculum where they were expected to finish it properly. This attitude indicates that academic inquisition and desire for efficiency in PBL facilitates positive outcome interdependence because structuring situations that support it results in increased effectiveness and productivity [26].

The students dealt with these perceptions through two measures. One was to speak up and share their academic inquiries, and the other was to seek each other's contributions to increase efficiency. These led to a mutually complementary behavior of wanting to share their ideas and learning achievements. We considered that the processes resulted in positive means interdependence because the process includes interaction patterns through task, role, and resource [4] . Because PBL was seen as a set task in an official curriculum, the students' willingness to complete the task may have promoted task interdependence. Then, when each student was expected to contribute to the promotion of task interdependence, the use of role interdependence was required. Some knowledgeable students and tutors were expected to have a role in making progress as well. We can observe these findings within the group discussion phase of PBL (e.g. steps $1-5$ in the seven-steps approach). The remaining steps are also related because step 6 is selfstudy for the complemented learning objectives and, in step 7, students integrate information within the group. Thus, while we have found contextual attributes within the discussion phase of PBL in this study, they presuppose the subsequent steps of self-study and learning integration. The students purposefully acted on the social interdependence described above for the sake of academic inquiry and efficiency. These behaviors are similar to previous research on non-learning environments. Wageman [27] explains that group achievement increases cooperation while the level of perceived effort affects the quality of group performance in his research at a large corporation.

The remaining component, boundary interdependence was also observed. Students were asked to understand the differences of opinion in their groups and to contribute their diverse perspectives based on those differences.
The findings we observed in this study are consistent with previous articles. For example, Torre et al. [28] claim that entitativity (the perception of a group as a single entity) is important in PBL because it affects the group's pursuit of common goals and group decisions. In addition, they also advocate that individual responsibility plays another key role in the collaboration [28]. Because the performance of a member affects the outcome of the whole group, each member feels responsible for the performance outcome. There is a concern that "social loafing" can lead to unproductive work in the group [29]. This is unlikely if discussion is well designed to establish individual accountability and engage personal performance with group achievement, including changing the group allocation process [30] and providing the underlying ideas of PBL [31].

Research shows that PBL cultivates social interdependence and offers a partial explanation of group dynamics in general [23], such as the success of group learning [32]. However, PBL does not only occur in group work; the perceptions and work of each participant affects discussions in the curricula of undergraduate health professions. The students are forced to think about individual achievement and learning outcomes as long as they receive the high-stakes assessment of themselves such as graduation test or national license examination in the near future [33]. Since group functioning and individual contributions are difficult to separate in terms of successful learning [19], it is necessary to assess not only knowledge but also group dynamics in PBL. The results of this study will contribute to that assessment through the lens of social interdependence.

Our findings also explain one of the situations that PBL did not function as expected. A report of the such situation in Asia [8] revealed that, the students were confused by the tutor's demand for self-directed learning, and the tutor was frustrated by the students' inability to deepen the discussion. There has also been debate about the reasons for the outcome that PBL did not work after implementing it. While they have been discussed as independent factors, our findings explain this phenomenon as a failure to provide efficiency in PBL because individual academic inquiry was not cultivated. As some educators pointed out [14], their PBL practices were not sufficiently linked to the achievement goals in their undergraduate program. Therefore, their PBL practices failed to evoke the academic inquiry that is essential for constructing academic goals within PBL. In addition, the East Asian emphasis on the significance of high-stakes testing in learning made students more aware of operational efficiency in learning rather than academic inquisition [33]. As a result, the students expected that someone who had enough knowledge to learn would take the initiative to guide them through 
the process. Hence, a side effect of the stronger burden on the tutors also manifested as a relative insufficiency of the tutors' skills [14]. Therefore, the process of exchanging and sharing ideas through discussion did not feel more efficient than independent study in the theoretical framework of social interdependence and did not create an environment for students to have constructive group discussions. Another argument about Asian students in PBL is that they typically avoid dialogues at the expense of their own interests [15]. Mutual contribution through dialogue will take a lot of time and undermines the efficiency of learning. If the tutor fails to arouse enough interest to merit discussion, the student will try to avoid dialogues and work through the discussion promptly.

Several factors inhibit the discussion phase of PBL, such as previous educational systems, tutor behavior, and assessment systems [16]. Our findings are consistent with these factors. If the existing educational system is passive in handling tasks, it must prioritize efficiency over academic inquiry. Students' expectations of tutor behavior would also be heavily weighted toward simply providing the knowledge that is required for learning. The response to high-stakes examinations also prioritizes efficiency. Regardless of whether this phenomenon is judged a "failure," it is an adaptation of PBL to the East Asian context [34].

Our findings can be used to improve PBL using SIT as a theoretical framework. It is necessary to strike a balance between academic inquiry and efficiency. As mentioned above, PBL practices in East Asia have overemphasized operational efficiency; therefore, instruction that can guide students to encourage academic inquiry would be useful. In the assessment, not only the acquisition of learning items, but also attitudinal items, such as outcomes and social interdependence in the means of learning, could be assessed. Since skills to promote positive social interdependence can be trained [35], any feedback provided through the lens of SIT may be useful.

This model could also be applied as an innovative tool for collaborative learning. One example is the enhancement of boundary interdependence by comparing the learning outcomes of groups, which is a strategy for creating boundary interdependence [36]. PBL is not fundamentally designed to compare learning achievement between groups, and we did not find any evidence that other groups influenced social interdependence in PBL. For example, if we could provide an opportunity for students to show their reaction towards the case beyond the group and discuss in a larger group, we could strengthen the processes of social interdependence in our model. Alternatively, future studies might include technology-enhanced learning, as technology will certainly contribute to future education [37], and online collaborative learning is becoming more popular [38]. However, problem-solving in the online environment is sometimes frustrating for students [39] since the quality of communication decreases in virtual discussions. There have been several reports on online or blended PBL, some of which succeeded in technically fostering the group process or improving the cooperation during the self-directed learning $[40,41]$. We should ensure positive social interdependence as much as possible based on our findings when we conduct further online or blended PBL. For example, using chat and response tools together to encourage participants to participate in discussions will make it easier to share them and make their contributions visible to each other [42]. In addition, using a learning management system to assess understanding instead of relying on tutors [43] would complement academic inquisition. These specific methods should be explored in future research.

\section{Strengths and limitations}

These findings might enable innovations that new intervention procedures can be suggested for tutors. Since tutor training is a crucial component of a successful PBL curriculum [44], various curricula to improve tutors' competencies in PBL have been implemented. For example, Azer [45] suggested twelve tips, such as building trust and encouraging the bonding of group members, as well as promoting group dynamics. However, balancing academic inquisition and desire for efficiency will be required in terms of positive social interdependence, in addition to group cohesiveness. For example, encouraging professional identity formation and self-directed learning attitude [46] by self-reflection about students' social expectations and personal identity as a future profession [47], may introduce student more academic inquisition and thus make PBL sessions more beneficial.

On the other hand, there are some limitations. First, we did not make assumptions about the cultural characteristics of the participants, which might affect the findings of our research, since we can refer the difference of social interdependence perception into rejection avoidance and harmony-seeking attitudes. According to their study, there is no difference in harmony seeking between Japan and the United States, but Japanese respondents reveal higher rejection avoidance. When the notion is transferred to this model, attitude to pursue desire for efficiency might be strengthened while sharing inquisition might be decreased.

In addition, the PBL tutor also served as the interview and analyst. It is possible that this may have had an impact on the collection and analysis of data from students. However, he was not involved in the summative assessment and he regularly reflected on the text and analysis 
with the other authors to reduce the impact as much as possible to ensure reflexivity of the research.

In conclusion, this study revealed that there were two contextual attributes (academic inquisition and desire for efficiency) for positive social interdependence in PBL based on analysis in an East Asian undergraduate context. In the pursuit of both academic inquiry and operational efficiency, students created a positive social interdependence that called for shared problem-solving and mutual contributions. From these findings, further analysis of the phenomena during discussions, training of tutors, and innovative learning environments are determined to be more effective in collaborative learning practices.

\section{Abbreviations}

PBL: Problem-based learning; SIT: Social interdependence theory

\section{Supplementary Information}

The online version contains supplementary material available at https://doi. org/10.1186/s12909-021-02667-y.

Additional file 1. List of interview guide.

\section{Acknowledgements}

We are grateful to Dr. Hideyuki Nakazawa, a director of Internal Medicine II in Shinshu University Hospital for promoting the convenience of the focus groups. We would also like to appreciate Editage (www.editage.com) for English language editing.

\section{Authors' contributions}

IS made substantial contributions to: conception and design, acquisition of data, analysis and interpretation of data as well as drafting the document the manuscript. YM made substantial contributions to: conception, design, analysis and interpretation of data as well as critically revising the manuscript. CvdV and RD made substantial contributions to: conception and design, analysis and drafting and critically revising the manuscript. All the authors approved the final version of the manuscript to be submitted. Each author has participated sufficiently in the work to take public responsibility for appropriate portions of the content and each has agreed to be accountable for all aspects of the work.

\section{Authors' information}

Ikuo Shimizu, MD, MHPE, is an assistant professor at Safety Management Office, Shinshu University Hospital, Japan, and a PhD candidate at School of Health Professions Education, Maastricht University, The Netherlands. Yasushi Matsuyama, MD, MHPE, PhD, is an Associate Professor of Medical Education Centre, Jichi Medical University, Japan.

Robbert Duvivier, MD, PhD, MBA, combines specialist training in psychiatry at Parnassia Mental Health in the Hague, the Netherlands, with research in education. He currently holds appointments at University Medical Centre Groningen, the Netherlands, and at the University of Newcastle, Australia where he is an Associate Professorin Medical Education.

C.P.M. van der Vleuten is a professor and scientific director, School of Health Professions Education, Department of Educational Development and Research, Faculty of Health, Medicine and Life Sciences, Maastricht University, Maastricht, The Netherlands.

\section{Funding}

This work was supported by the JSPS KAKENHI under Grant \#18 K17315. This funding source had no role in the design of this study and will not have any role during its execution, analyses, interpretation of the data, or decision to submit results.

\section{Availability of data and materials}

The datasets used and/or analyzed during the current study are available from the corresponding author on reasonable request.

\section{Declarations}

Ethics approval and consent to participate

This study was performed in accordance with the Declaration of Helsinki. Participants received a written informed consent form, and those who understood the purpose of the research and agreed to participate in the focus groups were included in the study. All the participants were informed that the participation was not mandatory and was not related to their grading.

This study was approved by the Institutional Review Board of Shinshu University (\#3719).

\section{Consent for publication}

Not applicable.

\section{Competing interests}

$\mathrm{RD}$ is an Associate editor of BMC Medical Education. The other authors have no competing interests.

\section{Author details}

${ }^{1}$ Center for Medical Education and Clinical Training, Shinshu University, 3-1-1 Asahi, Matsumoto 3908621, Japan. ${ }^{2}$ Medical Education Centre, Jichi Medical University, 3311-1 Yakushiji, Shimotsuke-shi, Tochigi, Japan. ${ }^{3}$ Center for Educational Development and Research in Health Sciences (CEDAR), University Medical Center Groningen, Antonius Deusinglaan 1, 9713 AV Groningen, The Netherlands. ${ }^{4}$ Department of Educational Development and Research, Faculty of Health, Medicine and Life Sciences, Maastricht University, Universiteitssingel 60, 6229 ER Maastricht, The Netherlands.

Received: 11 January 2021 Accepted: 13 April 2021

Published online: 21 April 2021

\section{References}

1. Schmidt HG. Problem-based learning: rationale and description. Med Educ 1983;17(1):11-6. https://doi.org/10.1111/j.1365-2923.1983.tb01086.x.

2. Savery JR, Duffy TM. Problem Based Learning: An instructional model and its constructivist framework. Constructivist Learning Environments: Case Studies in Instructional Design. In: Wilson BG, editor. Constructivist learning environments: Case studies in instructional design. Englewood Cliffs, $\mathrm{N}$ : Educational Technology Publications Englewood Cliffs; 1996. p. 135-48.

3. Gijselaers WH, Schmidt HG. Development and evaluation of a causal model of problem-based learning. In: Nooman Z, Schmidt HG, EE, editors. Innovation in medical education: An evaluation of its present status. New York: Springer Publishing; 1990. p. 95-113.

4. Johnson DW, Johnson RT. An Educational Psychology success story: social interdependence theory and cooperative learning. Educ Res. 2009;38(5): 365-79. https://doi.org/10.3102/0013189X09339057.

5. Johnson DW, Johnson RT. Cooperation and competition: theory and research: Central European; 1989.

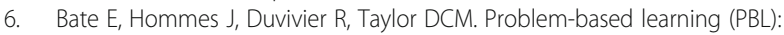
getting the most out of your students - their roles and responsibilities: AMEE guide no. 84. Med Teach. 2014;36(1):1-12. https://doi.org/10.3109/ 0142159x.2014.848269

7. Paradis E, Whitehead CR. Beyond the lamppost: a proposal for a fourth wave of education for collaboration. Acad Med. 2018;93(10):1457-63. https://doi.org/10.1097/acm.0000000000002233.

8. Kwan CY. A thorny path: the developmental course of problem-based learning for health sciences education in Asia. Adv Heal Sci Educ. 2019;24(5): 893-901. https://doi.org/10.1007/s10459-019-09920-6.

9. Davidson N, Major $\mathrm{CH}$. Boundary crossings: cooperative learning, collaborative learning, and problem-based learning. J Excell Coll Teach. 2014;25(3\&4):7-55.

10. Hommes J, Van De Bossche P, De Grave W, Bos G, Schuwirth LSA. Group development in a collaborative learning environment; 2012.

11. Smith G. Group development: a review of the literature and a commentary on future research directions. Gr Facil. 2001;3:14-44. 
12. Wheelan SA, Lisk AR. Cohort group effectiveness and the educational achievement of adult undergraduate students. Small Gr Res. 2000;31(6):72438. https://doi.org/10.1177/104649640003100605.

13. Arrow H, Scott Poole M, Henry KB, Wheelan S, Moreland R. Time, Change, and Development: The Temporal Perspective on Groups. Small Group Res. 2004;35(1):73-105.

14. Mathieu J, Maynard TM, Rapp T, Gilson L. Team effectiveness 1997-2007: A review of recent advancements and a glimpse into the future. J Manage. 2008;34(3):410-76

15. Oda Y, Koizumi S. Status of medical education reform at Saga medical school 5 years after introducing PBL. Kaohsiung J Med Sci. 2008;24(3):S4653. https://doi.org/10.1016/s1607-551x(08)70094-9.

16. Khoo HE. Implementation of problem-based learning in Asian medical schools and students' perceptions of their experience. Med Educ. 2003;37(5): 401-9. https://doi.org/10.1046/j.1365-2923.2003.01489.x.

17. Frambach JM, Driessen EW, Beh P, van der Vleuten CPM. Quiet or questioning? Students' discussion behaviors in student-centered education across cultures. Stud High Educ. 2014;39(6):1001-21. Available from:. https:// doi.org/10.1080/03075079.2012.754865.

18. Creswell JW. Educational research: planning, conducting, and evaluating quantitative and qualitative research. 4th ed. Vol. 4, educational research. Boston: Edweards Brothers; 2012

19. Kwok P. Examination-oriented knowledge and value transformation in east Asian cram schools. Asia Pacific Educ Rev. 2004;5(1):64-75. https://doi.org/1 $0.1007 /$ BF03026280.

20. Corbin J, Strauss A. Basics of qualitative research (3rd ed.): techniques and procedures for developing grounded theory. Thousand Oaks: SAGE Publications, Inc.; 2008. https://doi.org/10.4135/9781452230153.

21. Bergman E, de Feijter J, Frambach J, Godefrooij M, Slootweg I, Stalmeijer R, et al. AM last page: a guide to research paradigms relevant to medical education. Acad Med. 2012;87(4):545. https://doi.org/10.1097/acm.0b013e31824fbc8a.

22. De Grave WS, Boshuizen HPA, Schmidt HG, De Grave W. Problem based learning: cognitive and metacognitive processes during problem analysis. Instr Sci. 1996:24(5):321-41. https://doi.org/10.1007/BF00118111.

23. Hennink MM, Kaiser BN, Marconi VC. Code saturation versus meaning saturation: how many interviews are enough? Qual Health Res. 2017;27(4): 591-608. https://doi.org/10.1177/1049732316665344.

24. Shimizu I, Kikukawa M, Tada T, Kimura T, Duvivier R, van der Vleuten C. Measuring social interdependence in collaborative learning: instrument development and validation. BMC Med Educ. 2020;20(1):177. https://doi. org/10.1186/s12909-020-02088-3.

25. Visschers-Pleijers AJSF, Dolmans DHJM, Wolfhagen IHAP, Van Der Vleuten CPM. Exploration of a method to analyze group interactions in problembased learning. Med Teach. 2004;26(5):471-8. https://doi.org/10.1080/01421 590410001679064

26. Dolmans DHJM, De Grave W, Wolfhagen IHAP, Van Der Vleuten CPM. Problembased learning: future challenges for educational practice and research. Med Educ. 2005;39(7):732-41. https://doi.org/10.1111/j.1365-2929.2005.02205.x

27. Hagman J, Hayes J. Cooperative learning: Effects of task, reward, and group size on individual achievement. US Army Research Inst for the Behavioral and Social Sciences. Alexandria VA; 1986.

28. Wageman R. Interdependence and group effectiveness. Adm Sci Q. 1995; 40(1):145. https://doi.org/10.2307/2393703.

29. Torre DM, Van Der Vleuten C, Dolmans D. Theoretical perspectives and applications of group learning in PBL. Med Teach. 2015;38:189-95. https:// doi.org/10.3109/0142159X.2015.1009429.

30. Latané B, Williams K, Harkins S. Many hands make light the work: the causes and consequences of social loafing. J Pers Soc Psychol. 1979;37(6):822-32. https://doi.org/10.1037/0022-3514.37.6.822.

31. Kelly P. Achieving desirable group-work outcomes through the group allocation process. Team Perform Manag An Int J. 2008;14(1/2):22-38. https://doi.org/10.1108/13527590810860186

32. Moust JHC, Van Berkel HJM, Schmidt HG. Signs of erosion: reflections on three decades of problem-based learning at Maastricht University. High Educ. 2005;50(4):665-83. https://doi.org/10.1007/s10734-004-6371-z.

33. Hirokawa RY. Group communication and problem-solving effectiveness: an investigation of group phases. Hum Commun Res. 1983;9(4):291-305. https://doi.org/10.1111/j.1468-2958.1983.tb00700.x.

34. Lee $Y$, Roth $W$. The individual|collective dialectic in the learning organization. Learn Organ. 2007;14(2):92-107. https://doi.org/10.1108/ 09696470710726970.
35. Shimizu I, Nishigori $H$. Failure or adaptation? - redefining PBL from the perspective of the safety II paradigm. Med Teach. 2020;42(9):1076-7. https:// doi.org/10.1080/0142159x.2020.1729971.

36. Nam CW, Zellner RD. The relative effects of positive interdependence and group processing on student achievement and attitude in online cooperative learning. Comput Educ. 2011;56(3):680-8. https://doi.org/10.101 6/j.compedu.2010.10.010

37. Dolmans D, Michaelsen L, van Merriënboer J, van der Vleuten C. Should we choose between problem-based learning and team-based learning? No, combine the best of both worlds! Med Teach. 2015;37(4):354-359. https:// doi.org/10.3109/0142159x.2014.948828.

38. Harden RM. Ten key features of the future medical school — not an impossible dream. Med Teach. 2018;40(10):1010-5. https://doi.org/10.1080/ 0142159x.2018.1498613.

39. Ahmed $H$, Allaf M, Elghazaly H. COVID-19 and medical education. Lancet Infect Dis. 2020;20(7):777-8. https://doi.org/10.1016/s1473-3099(20)30226-7.

40. Valaitis RK, Sword WA, Jones B, Hodges A. Problem-based learning online: perceptions of health science students. Adv Heal Sci Educ. 2005;10(3):23152 Available from: http://link.springer.com/10.1007/s10459-005-6705-3.

41. Moeller S, Spitzer K, Spreckelsen C. How to configure blended problem based learning-results of a randomized trial. Med Teach. 2010;32(8):e328-46 https://doi.org/10.3109/0142159x.2010.490860.

42. Woltering V, Herrler A, Spitzer K, Spreckelsen C. Blended learning positively affects students' satisfaction and the role of the tutor in the problem-based learning process: results of a mixed-method evaluation. Adv Heal Sci Educ. 2009:14(5):725-38. https://doi.org/10.1007/s10459-009-9154-6.

43. Carvalho-Silva D, Garcia L, Morgan SL, Brooksbank C, Dunham I. Ten simple rules for delivering live distance training in bioinformatics across the globe using webinars. PLoS Comput Biol. 2018;14(11):1-10

44. Shimizu I, Nakazawa H, Sato Y, Wolfhagen IHAP, Könings KD. Does blended problem-based learning make Asian medical students active learners?: a prospective comparative study. BMC Med Educ. 2019;19(1):147. https://doi. org/10.1186/s12909-019-1575-1.

45. Farmer EA. Faculty development for problem-based learning. Eur J Dent Educ. 2004;8(2):59-66. https://doi.org/10.1111/j.1600-0579.2003.00337.x.

46. Azer SA. Challenges facing PBL tutors: 12 tips for successful group facilitation. Med Teach. 2005;27(8):676-81. https://doi.org/10.1080/01421 590500313001.

47. Wald HS. Professional identity (trans) formation in medical education. Acad Med. 2015;90(6):701-6. Available from: http://journals.lww.com/00001888-2 01506000-00008. https://doi.org/10.1097/ACM.0000000000000731.

\section{Publisher's Note}

Springer Nature remains neutral with regard to jurisdictional claims in published maps and institutional affiliations.

Ready to submit your research? Choose BMC and benefit from:

- fast, convenient online submission

- thorough peer review by experienced researchers in your field

- rapid publication on acceptance

- support for research data, including large and complex data types

- gold Open Access which fosters wider collaboration and increased citations

- maximum visibility for your research: over $100 \mathrm{M}$ website views per year

At BMC, research is always in progress.

Learn more biomedcentral.com/submission 